\title{
Percutaneous Selective Vertebroplasty: State of the Art Management in Well-Confined Metastatic Vertebral Lesions
}

\author{
Hossam Elnoamany \\ Department of Neurosurgical, Faculty of Medicine, Menoufia University Hospital, Shebin El Kom, Egypt
}

\section{Study Design: Prospective cohort study.}

Purpose: To evaluate the clinical and radiological results of percutaneous selective vertebroplasty (PSV) as first-line treatment options in the setting of well-confined spinal metastases.

Overview of Literature: Recent technological advances combined with innovative interventional techniques enable an alternative less invasive treatment option for many patients with malignant vertebral body infiltration. Percutaneous vertebral augmentation procedures offer less invasive but effective pain relief to many patients with symptomatic spinal metastatic disease.

Methods: Eleven patients with 21 well-confined metastatic vertebral lesions that had been treated with PSV were included. Pain was evaluated one week, one month, 3 months and 6 months post-procedure using a 10-point visual analogue scale (VAS). A statistical analysis including repeated measures analysis of variance test was used to collectively indicate the presence of any significant differences between different time sequences. Medication usage and range of mobility were also evaluated.

Results: The 11 patients had an average age of 42 years and $54.5 \%$ were male. Highly significant improvements in VAS scores at rest and with activity $(p<0.001)$ were evident. There was a significant decrease in rate of medication consumption post-procedure $(p<0.05)$.

Conclusions: PSV can be used successfully as the first-line treatment for well-confined metastatic vertebral lesions. It is also an effective method to decrease pain, increase mobility, and decrease narcotic administration in such patients.

Keywords: Metastatic spine; Osteolytic vertebral lesions; Percutaneous selective vertebroplasty; Pain measurement

\section{Introduction}

Bone is one of the most common sites of metastasis [1]. Metastatic spinal tumors are the most common type of bone metastasis, and $39 \%$ of bone metastases are located in the axial skeleton [2,3]. The most common sites of disease are the thoracic vertebrae $(60 \%-80 \%)$, followed by the lumbar spine (20\%) and cervical spine (10\%) [4]. Spinal metastases are observed in more than two-thirds of patients who succumb to cancer.

Spinal metastases are often seen in patients with breast, lung, and prostate cancers. The majority of spinal metastases are due to hematogenous spread; a small number of lymphatic metastases are also seen. The vertebral body

\footnotetext{
Received Nov 25, 2015; Revised Dec 17, 2015; Accepted Jan 10, 2016

Corresponding author: Hossam Elnoamany

Department of Neurosurgical, Faculty of medicine, University Hospital, Menoufia University,

64 Gamal abdel naser Street, Shebin el kom, Menoufia, Egypt

Tel: +2-010-0295305, Fax: +2-048-2233771, E-mail: Hae1967@gmail.com
} 
is much more easily damaged by spinal metastases than other parts of the vertebra due to its large volume and the abundance of blood vessels within it. Many tumor cells in spinal metastases produce and secrete osteoclast stimulating factors, thus enhancing bone absorption and leading to bone destruction [5].

The invasiveness of metastatic lesions in the vertebral body and its attachments results in spinal deformity and spinal instability [6]. This may cause severe thoracic and back pain, and even neurological dysfunction [7]. The quality of life and psychological state of patients with spinal metastases may be seriously affected.

Treatment of metastases to the spine is complex and challenging, and requires systemic and local therapies. The latter entail radiation therapy, surgical stabilization or vertebrectomy, and palliative therapy [8]. Since its introduction during the 1990s, percutaneous vertebroplasty $(\mathrm{PV})$ has been progressively developed and adopted to treat spinal metastases. It has even been included in some algorithms for the management of spinal metastases [1]. The two main indications for PV in the treatment of spinal metastases are analgesia and spine stabilization $[9,10]$.

The purpose of this study is to evaluate the clinical and radiological results of new percutaneous selective vertebroplasty (PSV) as the first-line treatment in the setting of spinal metastases.

\section{Materials and Methods}

\section{Demographic data}

A total of 11 patients with vertebral metastases (6 males and 5 females, average age 42 years) were included (Table 1). This study was approved by Institutional Review Board of Menoufia University. Written informed consent was obtained from all patients. All patients met the following inclusion criteria: presented with thoracolumbar and/or back pain, percussion pain and movement disorders of the thoracic and/or lumbar vertebrae; well-confined osteolytic vertebral lesion in lower thoracic and/or lumbar vertebrae; and intact posterior wall of the involved vertebral body. Patients complicated with severe bleeding, coagulation disorders, or severe lung diseases were excluded. Advanced cachexia and extreme physical weakness, osteolytic vertebral lesion that was not well confined to the vertebral body, destruction of any portion of the vertebral wall, and spinal cord involvement and paraplegia were also grounds for exclusion.

\section{PSV procedure}

The procedure was performed with the patient under conscious sedation or general anesthesia, and as specified previously $[11,12]$. All vertebroplasty procedures were performed under the guidance of C-arm fluoroscopy, and

Table 1. Shows demographic and preoperative clinical data

\begin{tabular}{|c|c|c|c|c|c|c|c|}
\hline \multirow{2}{*}{ No. } & \multirow{2}{*}{ Sex } & \multirow{2}{*}{$\begin{array}{c}\text { Age } \\
\text { (yr) }\end{array}$} & \multirow{2}{*}{ Affected levels } & \multirow{2}{*}{ Pathology } & \multicolumn{3}{|c|}{ Preoperative } \\
\hline & & & & & Pain score & Paine activity score & RDQ \\
\hline 1 & Male & 37 & $\mathrm{D} 8,9,10$ & Lung cancer & 9 & 10 & 19 \\
\hline 2 & Female & 33 & L3, L4 & Breast cancer & 8 & 9 & 18 \\
\hline 3 & Male & 45 & D12, L1, L2 & Prostate cancer & 8 & 8 & 18 \\
\hline 4 & Female & 35 & D12 & Breast cancer & 7 & 9 & 17 \\
\hline 5 & Male & 36 & D12, L1 & Prostate cancer & 7 & 8 & 21 \\
\hline 6 & Male & 47 & D10 & Lung cancer & 8 & 9 & 21 \\
\hline 7 & Female & 71 & D9, D10 & Hepatic cancer & 8 & 9 & 20 \\
\hline 8 & Female & 39 & D12 & Breast cancer & 7 & 8 & 20 \\
\hline 9 & Male & 51 & L1, L3, L4 & Prostate cancer & 9 & 10 & 20 \\
\hline 10 & Male & 35 & D12, L4 & Gastric cancer & 8 & 8 & 19 \\
\hline 11 & Female & 34 & D12 & Lung cancer & 7 & 8 & 19 \\
\hline
\end{tabular}

RDQ, Ronald-Morris Disability Questionnaire. 
a 9-gauge needle (Tsunami Medical, Mirandola, Italy) was used to traverse the right, left, or both pedicles. The needle was introduced under continuous fluoroscopic guidance into the center of the osteolytic vertebral lesion as much as possible, without compromising the medial wall of the pedicle or the anterior cortex of the vertebral body. Once the needle had been inserted into the osteolytic cavity, the metastatic tissues were aspirated through the needle until surgeon achieved negative pressure in the biopsy needle for histopathological diagnosis and to decrease the intraverebral pressure. The needle was then cleared with saline and aspirated until negative pressure was achieved again. Acrylic resin was used (Exolent Spine, Elmdown, Italy). Cement was injected into the partially evacuated oseolytic lesion until it was just fully filled. No further cement injection was done. Patients were kept supine for 2 hours after the procedure before discharged next day.

\section{Outcome measurements}

Patients approved for PSV were evaluated preoperatively and postoperatively for both quantitative and qualitative measurements. Quantitative measurements were collected by using the Roland-Morris Disability Questionnaire (RDQ) [13] and the visual analog scale (VAS) for pain at rest and pain with activity, with zero being no pain and 10 being the worst pain ever experienced. Qualitative data were also collected. The preoperative data were collected in the hospital. Follow-up data were collected at 1 week, 1 month, 3 months, and 6 months.

\section{Statistical analyses}

Results were collected, tabulated, and statistically analyzed using SPSS ver. 16 software (SPSS Inc., Chicago, IL, USA). Repeated measures analysis of variance is a single test used to collectively indicate the presence of any significant difference between different time sequences for a normally distributed quantitative variable with Bonferroni as a post hoc test. A $p<0.05$ was considered significant.

\section{Results}

The 11 patients comprised 21 involved vertebral bodies, which involved the L4 ( $n=3), \mathrm{L} 3(\mathrm{n}=2), \mathrm{L} 2(\mathrm{n}=1), \mathrm{L} 1(\mathrm{n}=3)$, T12 $(n=6)$, T10 $(n=3)$, T9 $(n=2)$, and T8 $(n=1)$ vertebrae. Three patients had three affected vertebrae, four patients had two affected vertebrae and four patients had a single vertebra affected. The sources of metastases included lung cancer $(n=3)$, breast cancer $(n=3)$, prostate cancer $(n=3)$, gastric cancer $(n=1)$, and hepatic cancer $(n=1)$. Histological diagnosis was made in eight cases by needle biopsy aspiration in the beginning of the maneuver and in the remaining three cases after surgical removal of the primary tumor and confirmed by aspiration biopsy.

Mobility and early medication usage data were collected preoperatively. Regarding mobility in the 11 patients, four $(36.4 \%)$ patients could walk 50 meters or more, five (45.4\%) patients could walk less than 50 meters, and two (18.2\%) patients were bedridden. There was a highly significant improvement in mobility range postoperative throughout the whole period of follow-up $(p<0.001)$ (Table 2).

For medication usage, all patients were on a regular regimen of analgesics and /or narcotics. All patients were evaluated with preoperative X-ray, computed tomography bone window with reconstruction, and spinal magnetic resonance imaging (MRI). PSV was performed on nine patients with conscious sedation and two with general anesthesia. The average cement volume injected into each vertebra was $2.5 \mathrm{~mL}$ (range, $2-3 \mathrm{~mL}$ ).

A highly significant decrease in RDQ scores in all periods of follow-up was found $(p<0.001)$ (Fig. 1).

Quantitatively, highly significant decrease in pain was found, compared with preoperative values, in pain at rest 1 week, 1 month, 3 months, and 6 months postoperatively (all $p<0.001$ ) (Table 3 ). With activity, a highly significant decrease in pain at 1 week, 1 month, 3 months, and 6 months postoperative follow-up was also found (all $p<0.001$ ) (Table 4).

Bone cement leakage occurred in one thoracic vertebral

Table 2. Shows the percentage of improvement in all patients regarding mobility following PSV

\begin{tabular}{cccccc} 
& 1 week & 1 month & 3 months & 6 months & $p$-value \\
$\%$ of mobility improvement & $72.7 \%(8 / 11)$ & $90.9 \%(10 / 11)$ & $100 \%$ & $100 \%$ & $<0.001$ \\
\hline
\end{tabular}

PSV, percutaneous selective vertebroplasty. 
body in the pararvertebral area. No spinal cord compression or other complications such as pulmonary embolism and infection was observed. Patients were followed up for 6 to 14 months (mean, 9 months).

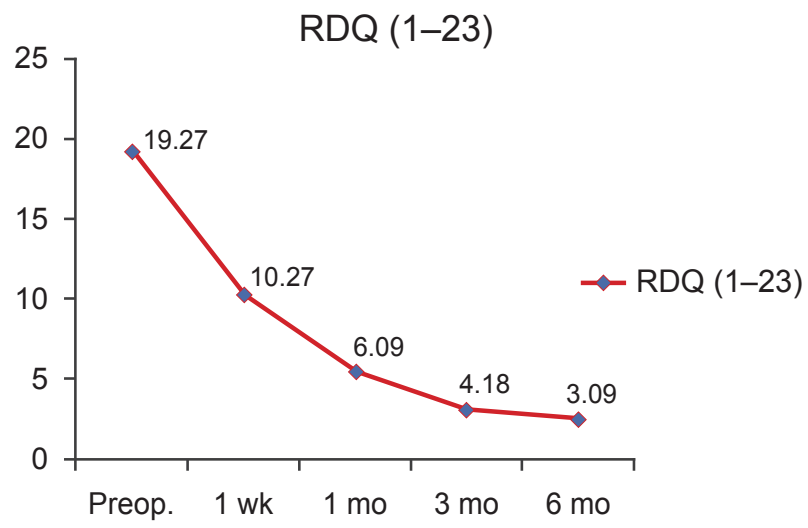

Fig. 1. GGraph of average RDQ scores following PSV. RDQ, RonaldMorris Disability Questionnaire; Preop, preoperative; PSV, ercutaneous selective vertebroplasty.

\section{Case presentation}

A 47-year-old man had a history of metastatic lung carcinoma and a pathological fracture involving the 10th thoracic vertebral body. The patient presented complaining of back pain in the lower thoracic area for 3 months that progressively became severe; at presentation the patient rated the pain as 9 on the 10-point VAS scale. MRI of the vertebral column showed a lytic metastasis within the 10th vertebral body that was well confined to the body of vertebra (Fig. 2A, B). Through a left costopedicular approach, a 9-gauge needle was used to aspirate the contents of the lytic lesion, followed by a saline wash. PSV was done to fully fill, but not overfill, he empty lytic lesion. Complete filling of the lytic focus within the left aspect of the vertebral body with $2.5 \mathrm{~mL}$ of cement was achieved. The cement demonstrated a nearly focal appearance within the lytic lesion (Fig. 2C-F). Following the procedure, pain was rated 1 week, 1 month, 3 months, and 6 months postoperatively; the VAS value was 5, 4, 3,

Table 3. Repeated measures ANOVA for VAS at different time sequences

\begin{tabular}{|c|c|c|c|c|c|c|c|}
\hline VAS & Preop. & Week 1 & Month 1 & Month 3 & Month 6 & $\begin{array}{c}\text { Repeated } \\
\text { measures } \\
\text { ANOVA }\end{array}$ & $p$-value \\
\hline Mean $\pm S D$ & $7.73 \pm 0.90$ & $4.73 \pm 0.78$ & $3.27 \pm 0.46$ & $2.18 \pm 0.40$ & $1.82 \pm 0.40$ & 269.99 & $<0.001$ \\
\hline \multicolumn{8}{|l|}{ Bonferroni } \\
\hline Preop. & - & $<0.001$ & $<0.001$ & $<0.001$ & $<0.001$ & & \\
\hline Week 1 & - & - & $<0.001$ & $<0.001$ & $<0.001$ & & \\
\hline Month 1 & - & - & - & $<0.001$ & $<0.001$ & & \\
\hline Month 3 & - & - & - & - & $>0.05$ & & \\
\hline
\end{tabular}

ANOVA, analysis of variance; VAS, visual analogue scale; Preop., preoperative; SD, standard deviation.

Table 4. Repeated measures ANOVA for VAS with activity at different time sequences

\begin{tabular}{|c|c|c|c|c|c|c|c|}
\hline $\begin{array}{l}\text { VAS with } \\
\text { activity }\end{array}$ & Preop. & Week 1 & Month 1 & Month 3 & Month 6 & $\begin{array}{c}\text { Repeated } \\
\text { measures } \\
\text { ANOVA }\end{array}$ & $p$-value \\
\hline Mean \pm SD & $8.73 \pm 0.78$ & $6.36 \pm 0.50$ & $3.91 \pm 0.53$ & $3.09 \pm 0.30$ & $2.91 \pm 0.30$ & 368.29 & $<0.001$ \\
\hline \multicolumn{8}{|l|}{ Bonferroni } \\
\hline Preop. & - & $<0.001$ & $<0.001$ & $<0.001$ & $<0.001$ & & \\
\hline Week 1 & - & - & $<0.001$ & $<0.001$ & $<0.001$ & & \\
\hline Month 1 & - & - & - & $<0.01$ & $<0.001$ & & \\
\hline Month 3 & - & - & - & - & $>0.05$ & & \\
\hline
\end{tabular}

ANOVA, analysis of variance; VAS, visual analogue scale; Preop., preoperative; SD, standard deviation. 

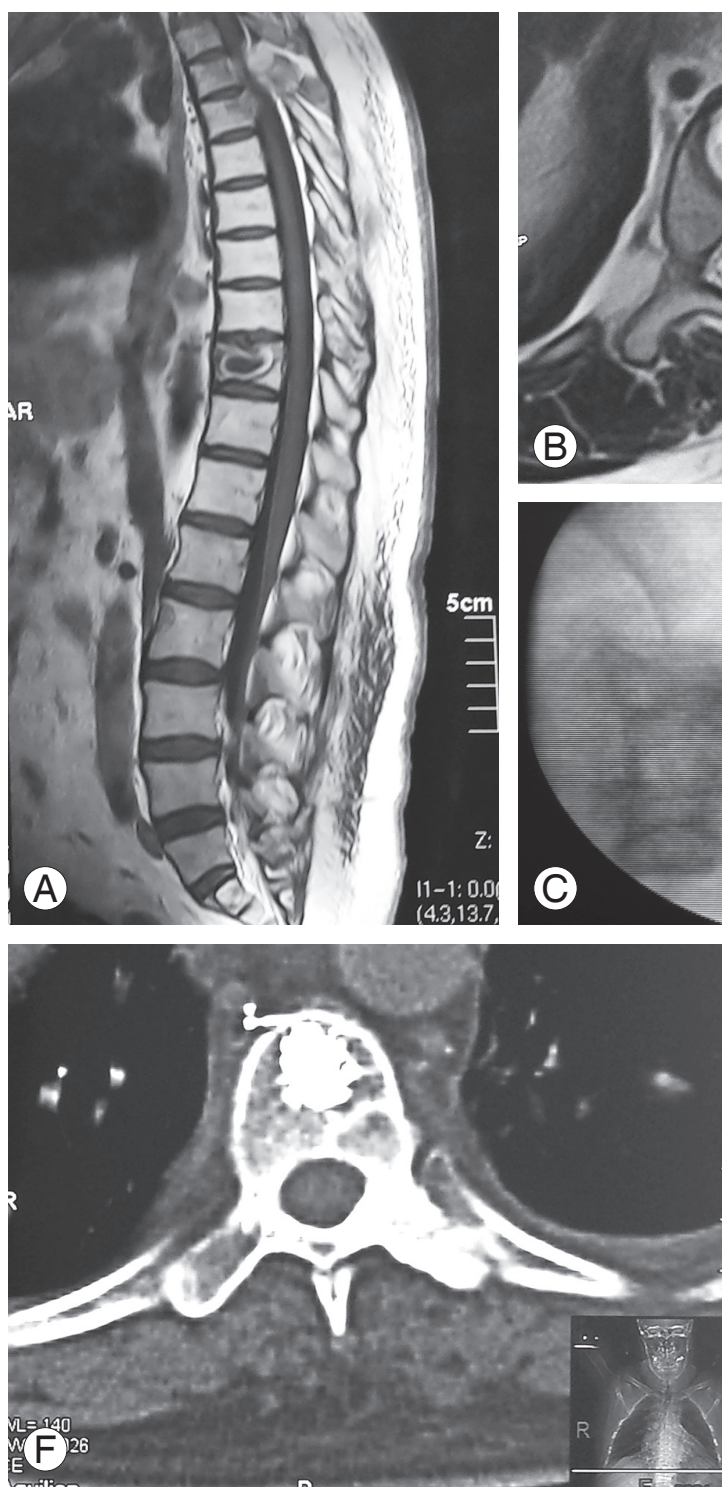

and 2 , respectively.

\section{Discussion}

Spinal metastases have a huge impact on the quality of lives of millions of people worldwide. Each year $5 \%$ of cancer patients develop spinal metastases, with the most common primary sites being breast, lung, and prostate [14]. Patients with spinal metastases have a median survival of 10 months, and effective palliation of symptoms is the principle clinical objective [15].

Since the destruction of metastatic tumors is mostly osteolytic, it often results in bone defects. The vertebral compression fracture occurs when the spine bears the body weight and consequently increases pain and even
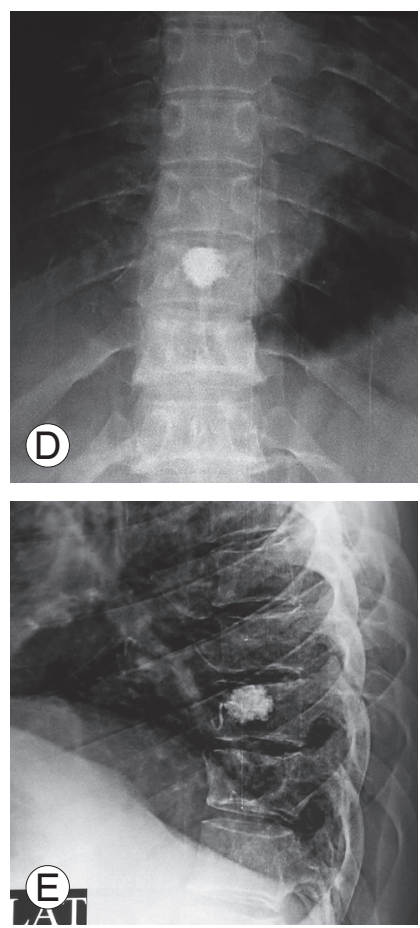

Fig. 2. (A) T1 weighted magnetic resonance imaging (MRI) sagittal view showing well defined osteolytic cavity in D10, (B) T2weighted MRI axial view showing well defined osteolytic cavity in D10, (C) intraoperative fluoroscopic picture lateral view showing focal cement filling in the ostelytic cavity, (D) postoperative X-ray anteroposterior view showing focal cement filling in the ostelytic cavity of D10, (E) postoperative X-ray lateral view showing focal cement filling in the ostelytic cavity of D10, and (F) 3-month postoperative computed tomography axial image showing the focal appearance of the cement in the injected vertebral cavity.

causes neurological symptoms [16-18].

Although the effect of open surgical treatment in recent years has been improved greatly and the surgical indications have also been expanded along with the improvement of spinal surgery techniques, treating spinal metastasis remains a big challenge $[19,20]$. Surgical spinal procedures are highly invasive in nature and are generally not suitable in this group of patients because of the high surgical risk of complications and the short life expectancy of this patient group. On the other hand, conventional radiotherapy and/or chemotherapy achieve only limited results and still have less than ideal therapeutic effect on such cases. Moreover, it cannot relieve the unstable spine as it does not treat the vertebral cavitations and spinal cord compression caused by the invasiveness of tumors 
[21-23]. So, such a group of patients need much more simple maneuvers to treat them.

Vertebroplasty has been in clinical use for a number of years $[11,24-27]$ and is considered the only treatment that actually manages the pain problem raised from weakened vertebra caused by osteolytic vertebral lesion. Until now, it has not been used as first-line treatment options in the setting of spinal metastases largely due to a lack of technical expertise in combination with insufficient outcome data from preliminary clinical trials. It offers alternative and less invasive treatment options for many patients with malignant vertebral body infiltration.

The injection of bone cement can strengthen the vertebral structure and sometimes restore the height, and improve pressure and intensity of vertebral bodies. In addition, the heat of the injected cement and monomer has antitumor effects, which reduce the local tumor burden and consequently reduce the destruction of local tumors on bones [28]. All these effects significantly prevent the vertebral bodies from further collapse and from invasion of the spinal tumors.

In the past, such patients used to be treated by radiation therapy first before referral to a spine surgeon. The results of radiotherapy is not convincing until now as published before [21-23], we believe it is duo to first; the radiation faces large area full of tumor tissues and secondly; it did not treat the problems that arise from lytic vertebral lesion.

The patients in this study were treated using PSV technique as all of them had only a well confined vertebra osteolytic lesions and they do not have any disrupted vertebral wall. Use of the PSV technique can achieve dual benefits; tumor tissues in the osteolytic lesion are reduced by aspiration using a 9-gauge needle and the lytic lesion is selectively filled by cement to enhance spinal stability and relieve back pain.

Since PV was first applied in the treatment of spinal metastases in 1989 [29], good results have been achieved $[10,24,30]$. In the present study, 11 patients with 21 well confined osteolytic metastatic lesions were treated using PSV. The majority (73\%) achieved significant pain relief with activity $(p<0.001)$ at 1 week postoperatively with subsequent improvement in their mobility. The progressive improvement in patient activity in this study was unusual. The usual activity improvement is immediate and worsens gradually with time. We believe that the present unusual results reflect three aspects. First, we included only patients with confined osteolytic lesions. Second, the follow-up period was not so long. Third, patients with bad general condition were excluded from this study cohort.

During the follow-up, all patients showed satisfactory results based on the significant reduction of opiate doses needed $(p<0.05)$. The present report is the first prospective cohort case study that showed the dual benefits of PSV in achieving good results in well confined vertebral metastatic lesions.

However, the evaluation of the treatment efficacy of PV on vertebral metastases is mainly based on pain relief. The simple application of pain relief assessment cannot fully reflect the patient's quality of life. In the present study, RDQ scores were used to assess clinical improvements following PSV. There was a very significant reduction in RDQ scores after the application of PSV in the treatment of vertebral metastases, which comprehensively improved quality of life.

Previously, Cotten et al. [24] stated that the degree of pain reduction does not correlate with the degree of PMMA cement filling of an osteolytic metastasis seen with CT examinations. Despite our patients treated with the current PSV technique only underwent cementing of osteolytic cavities. All patients showed highly significant pain reduction.

This study is totally different from previous published data $[9,21,24,30,31]$. The amount of injected cement was much less than previously known $[9,21,24,31]$. The amount of injected cement ranged from $2-3 \mathrm{~mL}$ in this study, because our patients only underwent cementing of the osteolytic lesion only and not the whole affected vertebrae.

Despite the small amount of the injected cement in the present study, the results of our patients are comparable to those previously published for cementing the whole affected vertebra $[9,10,21,24,31]$. Regarding the current radiological results, as we only cement the osteolytic lesion we did not encounter any complications that can be related to the amount of the cement injected such as cement leak, embolism, adjacent vertebral fracture, and any vertebral fractures in the injected vertebrae itself. At the 6-month follow-up no case of recurrent tumor in the previously injected vertebrae was encountered in this patient cohort.

A review of all major vertebroplasty series in welltrained hands had a clinical complication rate of $10 \%$ in patients with metastasis to the vertebra [27]. Mousavi et al. [32] reported that the risk of cement leakage during 
PV in the metastatic spine is significant, with $85.7 \%$ of procedures resulting in cement extravasation outside of the vertebral body. However, extravasation in these cases is not usually clinically significant.

The higher risk of extravasation in patients with spinal malignancy, compared with patients with osteoporotic vertebrae, may be attributed to the increased in situ pressures generated during the procedure [33]. Injection of bone cement into a vertebral body with a resident tumor is more difficult than injection into an osteoporotic vertebral body. By using the PSV technique, we first aspirated the tumor tissues until negative pressure was attained in the aspirating needle to minimize the intravertebral pressure as much as possible to safely cement the osteolytic lesion. Also, we only cemented the ostelytic lesion until reaching the characteristic focal-like appearance of the cement under fluoroscopic imaging before any cement extravasation outside the cavity and subsequently the vertebral body. So, by using the PSV technique, we did not encounter any cases of symptomatic cement leak.

Partially aspirating the tumor tissues and subsequently reducing the cement injection pressure as a first step in PSV technique reduces another important concern-the potential for eliciting tumor cell extravasation-that has deterred many clinicians in the past from using percutaneous vertebral body augmentation as a treatment option for patients with spinal metastasis.

\section{Conclusions}

This report described a new PSV technique which is selective technique of performing PV in patients suffering from metastatic osteolytic vertebral lesions. This unique dual action of PSV technique increases benefits to patients suffering from osteolytic metastatic spinal lesions. Aspirating the tumor tissues and selective filling of a lytic metastasis with cement correlates with favorable patient outcomes and prevents the vertebral bodies from further collapse and from invasion of the spinal tumors. This technique has no mentioned serious complications and we can consider it as first line treatment options in the setting of spinal metastases.

\section{Conflict of Interest}

No potential conflict of interest relevant to this article was reported.

\section{Acknowledgments}

Thanks to Dr. Zeinab Abdel Aziz Kasemy, Lecturer of public Health and Community Medicine, Menoufiya University for doing statistics in this study.

\section{References}

1. Barragan-Campos HM, Vallee JN, Lo D, et al. Percutaneous vertebroplasty for spinal metastases: complications. Radiology 2006;238:354-62.

2. Tatsui $H$, Onomura T, Morishita S, Oketa M, Inoue T. Survival rates of patients with metastatic spinal cancer after scintigraphic detection of abnormal radioactive accumulation. Spine (Phila Pa 1976) 1996; 21:2143-8.

3. Berrettoni BA, Carter JR. Mechanisms of cancer metastasis to bone. J Bone Joint Surg Am 1986;68:30812.

4. Thanos L, Mylona S, Galani P, et al. Radiofrequency ablation of osseous metastases for the palliation of pain. Skeletal Radiol 2008;37:189-94.

5. Xie L, Chen Y, Zhang Y, et al. Status and prospects of percutaneous vertebroplasty combined with (1)(2)(5) I seed implantation for the treatment of spinal metastases. World J Surg Oncol 2015;13:119.

6. Gokaslan ZL, York JE, Walsh GL, et al. Transthoracic vertebrectomy for metastatic spinal tumors. J Neurosurg 1998;89:599-609.

7. Masala S, Anselmetti GC, Muto M, Mammucari M, Volpi T, Simonetti G. Percutaneous vertebroplasty relieves pain in metastatic cervical fractures. Clin Orthop Relat Res 2011;469:715-22.

8. Brado M, Hansmann HJ, Richter GM, Kauffmann GW. Interventional therapy of primary and secondary tumors of the spine. Orthopade 1998;27:269-73.

9. Weill A, Chiras J, Simon JM, Rose M, Sola-Martinez T, Enkaoua E. Spinal metastases: indications for and results of percutaneous injection of acrylic surgical cement. Radiology 1996;199:241-7.

10. Deramond H, Depriester C, Galibert P, Le Gars D. Percutaneous vertebroplasty with polymethylmethacrylate. Technique, indications, and results. Radiol Clin North Am 1998;36:533-46.

11. Jensen ME, Evans AJ, Mathis JM, Kallmes DF, Cloft HJ, Dion JE. Percutaneous polymethylmethacrylate vertebroplasty in the treatment of osteoporotic ver- 
tebral body compression fractures: technical aspects. AJNR Am J Neuroradiol 1997;18:1897-904.

12. Koch CA, Layton KF, Kallmes DF. Outcomes of patients receiving long-term corticosteroid therapy who undergo percutaneous vertebroplasty. AJNR Am J Neuroradiol 2007;28:563-6.

13. Trout AT, Kallmes DF, Gray LA, et al. Evaluation of vertebroplasty with a validated outcome measure: the Roland-Morris Disability Questionnaire. AJNR Am J Neuroradiol 2005;26:2652-7.

14. Jemal A, Thun MJ, Ries LA, et al. Annual report to the nation on the status of cancer, 1975-2005, featuring trends in lung cancer, tobacco use, and tobacco control. J Natl Cancer Inst 2008;100:1672-94.

15. Kassamali RH, Ganeshan A, Hoey ET, Crowe PM, Douis $\mathrm{H}$, Henderson J. Pain management in spinal metastases: the role of percutaneous vertebral augmentation. Ann Oncol 2011;22:782-6.

16. Anselmetti GC, Marcia S, Saba L, et al. Percutaneous vertebroplasty: multi-centric results from EVEREST experience in large cohort of patients. Eur J Radiol 2012;81:4083-6.

17. Masala S, Massari F, Fiori R, Mammucari M, Bartolucci DA, Simonetti G. Future directions in percutaneous vertebroplasty. Radiol Med 2009;114:976-83.

18. Garland P, Gishen P, Rahemtulla A. Percutaneous vertebroplasty to treat painful myelomatous vertebral deposits-long-term efficacy outcomes. Ann Hematol 2011;90:95-100.

19. Simmons ED, Zheng Y. Vertebral tumors: surgical versus nonsurgical treatment. Clin Orthop Relat Res 2006;443:233-47.

20. Lee B, Franklin I, Lewis JS, et al. The efficacy of percutaneous vertebroplasty for vertebral metastases associated with solid malignancies. Eur J Cancer 2009; 45:1597-602.

21. Chen LH, Hsieh MK, Niu CC, Fu TS, Lai PL, Chen WJ. Percutaneous vertebroplasty for pathological vertebral compression fractures secondary to multiple myeloma. Arch Orthop Trauma Surg 2012;132:75964.

22. Brown DB, Gilula LA, Sehgal M, Shimony JS. Treatment of chronic symptomatic vertebral compression fractures with percutaneous vertebroplasty. AJR Am J Roentgenol 2004;182:319-22.

23. Jacofsky DJ, Papagelopoulos PJ, Sim FH. Advances and challenges in the surgical treatment of metastatic bone disease. Clin Orthop Relat Res 2003;(415 Suppl):S14-8.

24. Cotten A, Dewatre F, Cortet B, et al. Percutaneous vertebroplasty for osteolytic metastases and myeloma: effects of the percentage of lesion filling and the leakage of methyl methacrylate at clinical follow-up. Radiology 1996;200:525-30.

25. Kaemmerlen $\mathrm{P}$, Thiesse $\mathrm{P}$, Jonas $\mathrm{P}$, et al. Percutaneous injection of orthopedic cement in metastatic vertebral lesions. N Engl J Med 1989;321:121.

26. Cortet B, Cotten A, Boutry N, et al. Percutaneous vertebroplasty in the treatment of osteoporotic vertebral compression fractures: an open prospective study. J Rheumatol 1999;26:2222-8.

27. Elnoamany H. Percutaneous vertebroplasty: a first line treatment in traumatic non-osteoporotic vertebral compression fractures. Asian Spine J 2015;9:17884.

28. Kallmes DF, Comstock BA, Heagerty PJ, et al. A randomized trial of vertebroplasty for osteoporotic spinal fractures. N Engl J Med 2009;361:569-79.

29. Kaemmerlen P, Thiesse P, Bouvard H, Biron P, Mornex F, Jonas P. Percutaneous vertebroplasty in the treatment of metastases. Technic and results. J Radiol 1989;70:557-62.

30. Gangi A, Dietemann JL, Guth S, Steib JP, Roy C. Computed tomography (CT) and flouroscopy-guided vertebroplasty: results and complications in 187 patients. Semin Intervent Radiol 1999;16:137-42.

31. Chiras J DH. Complications des vertebroplasties. In: Saillant G, Laville C, editors. Echecs et complications de la chirurgie du rachis: chirurgie de reprise, 1eres jounees internationales, R. Roy Camille, du rachis, Paris, 1996. Montpellier: Sauramps Medical; 1996. p.149-53.

32. Mousavi P, Roth S, Finkelstein J, Cheung G, Whyne C. Volumetric quantification of cement leakage following percutaneous vertebroplasty in metastatic and osteoporotic vertebrae. J Neurosurg 2003;99:56-9.

33. Reidy D, Ahn H, Mousavi P, Finkelstein J, Whyne CM. A biomechanical analysis of intravertebral pressures during vertebroplasty of cadaveric spines with and without simulated metastases. Spine (Phila Pa 1976) 2003;28:1534-9. 